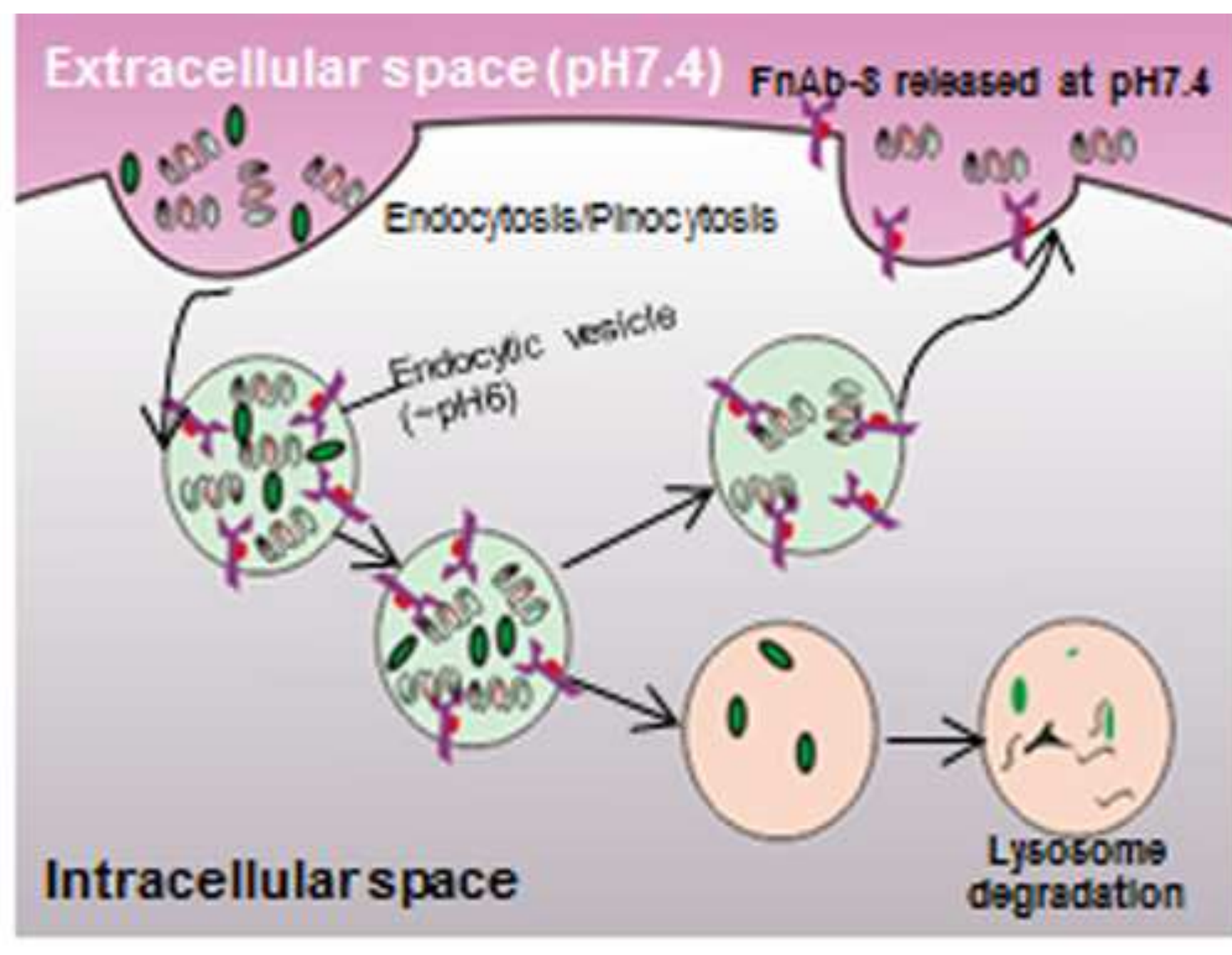

\section{'Graphical Abstract}

0 serum proteln

\section{Legend:}

w Forn

$01000 \quad F n A D-8$

cor
DOJO FRAD-8

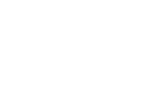

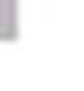

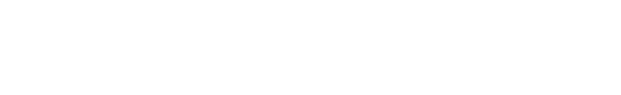


Single chain antibody fragments with $\mathrm{pH}$ dependent binding to FcRn enabled prolonged circulation of therapeutic peptide in vivo

Yangsheng Qiu, Wei Lv, Min Xu, Yuhong Xu*

School of Pharmacy, Shanghai Jiao Tong University, 800 Dongchuan Rd, Shanghai, 200240, PR China

*Corresponding author: School of Pharmacy, Shanghai Jiao Tong University, 800 Dongchuan Rd, Shanghai, 200240, PR China. Electronic address: yhxu@sjtu.edu.cn

\section{Abstract}

The neonatal Fc receptor for IgG (FcRn) is considered critical for the regulation of endogenous IgG and serum albumin (SA) and their circulation half-life in vivo. Both IgG and SA can bind to FcRn tightly at acidic $\mathrm{pH}$ but not so much at neutral $\mathrm{pH}$. Here we reported a few novel single chain antibody fragments (scFv) obtained based on screening of a phage library. FnAb-8 and FnAb-12 can bind to human FcRn with higher affinities than IgG at acidic pH but similar or lower affinities than IgG at pH 7.4. Fusion proteins consisted of the therapeutic peptide, GLP-1 (Glucagon-like peptide-1) connected to the N-terminus of FnAb-8 and FnAb-12, named as G8 and $\mathrm{G} 12$, were shown to retain the $\mathrm{pH}$-dependent binding capabilities to $\mathrm{FcRn}$ while also bound to the GLP-1 receptor. In vivo efficacy studies in diet induced diabetes mice confirmed the GLP-1 receptor (GLP-1R) agonist activities and sustained blood sugar lowering effect. In vivo pharmacokinetics (PK) studies were performed in nonhuman primates and FnAb-8 was found to have circulation half-life several folds longer than what have been reported for scFvs. G8 may be developed into long acting GLP-1R agonists with great potentials in clinical applications.

Keywords: FcRn, scFv, phage display, pH-dependent, half-life extension

\section{Introduction}

The neonatal Fc receptor ( $F c R n)$ is well known for having the functions of transporting IgGs across fetal and neonatal tissue barriers and regulating the rate of IgG and SA degradation throughout life [1-3]. It was firstly identified from the neonatal rodent gut which led to its designation as the neonatal Fc receptor (FcRn) $[4,5]$. The expression of FcRn was originally believed to be restricted to those sites involved in the transport of maternal IgG from mother to fetus or neonatal [6-8]. However, the presence of FcRn have now been extensively reported in many tissues and cell types including the endothelial cells, epithelial cells, the majority of hematopoietic cells, and some specialized cells such as podocytes, keratinocytes, the blood brain barrier endothelia, and the ocular cells [9-14].

Human FcRn was characterized as a heterodimer of one $\beta 2$-microglobulin (14 kDa) light chain and one $\alpha$ heavy chain (46 kDa), structurally homologous to the MHC class I molecule [15, 16]. The binding of both IgG and SA to FcRn were found to be highly $\mathrm{pH}$ dependent, with high affinity at acidic $\mathrm{pH}$ and low affinity at neutral $\mathrm{pH}$ [17-20]. They were protected from degradation based on a similar mechanism although through different binding sites [21-23]. Specifically, serum proteins including IgG and SA in circulation are taken up by myeloid cells or 
endothelial cells without FcRn binding near the cell surface when the $\mathrm{pH}$ is close to neutral. Entry of IgG and SA into cells is followed by accumulation in early endosomes where the acidic $\mathrm{pH}$ is permissive for FcRn binding. Then the early endosomes containing complex of FcRn and IgG/SA are sorted to recycle back to cell surface and IgG/SA released by exocytic processes close to the physiological $\mathrm{pH}$ [24-28].

Many studies had used the FcRn binding domains from SA or IgG and made fusion proteins containing these domains to achieve recycling and circulation extension [29-32], there had been also some efforts made to improve drugs' circulation properties by engineering or developing new peptide or protein binding domains of FcRn [33-43]. But most of these attempts including Fc-fusion proteins could not match the endogenous IgGs' long circulation half-life. Higher binding affinity at endosomal pH may not always translate to half-life extension [44, 45]. Other factors including the binding sites, $\mathrm{pH}$ dependency, and possibly affinity thresholds at different $\mathrm{pHs}$ may exist that governed the FcRn mediated recycling process [46].

In this study, we seek to explore whether it is possible to generate small affinity antibody fragments, i.e., single chain variable fragment (scFv Abs), that can interact directly with human $\mathrm{FcRn}$ in a pH-dependent way. The scFv fragments should have higher binding affinity at pH6.0 towards FcRn than those of hlgG or SA, but almost no binding at pH7.4. A specific scFv screening scheme was devised and successfully implemented. The detailed characterizations of the screen results indicated they may have excellent recycling properties and could be used as a long circulation carrier for therapeutical proteins and peptides.

2. Materials and methods

\subsection{Materials}

Human serum albumin (SA) was purchased from Abcam. Human IgG and HLA-A2 proteins, Lipofectamine2000, 293fectine and AF647 (AlexaFluor647) antibody labeling kit were from Invitrogen. Mouse anti-M13 phage antibody, anti-Poly-histidine tag antibody and GLP-1 were purchased from Genscript. GLP-1R-Fc, $\beta 2$-microglobulin ( $\beta 2 \mathrm{M}$ ) protein, $\beta 2 \mathrm{M}$ expression vector, FcRn and HLA-A2 cDNAs were obtained from Sinobiological. Anti-hFcRn and anti-HLA-A2 antibodies were from Santa-Cruz. Strepavidin-AF647, anti-mouse IgGAF647, anti-mouse-IgG-HRP were from Jackson Immunology research. Streptavidin-coupled Dynabeads was from ThermoFisher. Biotin labelling kit was from SoluLink. The luciferase assay system was from Promega. Cell culture medium and reagents were all purchased from GIBCO. Anti-FLAG magnetic beads and other chemicals were from Sigma-Aldrich.

\subsection{Protein Expression}

Soluble extracellular domains of human, cynomolgus and mouse FcRn were cloned, expressed, and purified based on a previous study [47]. Briefly, the cDNA encoding extracellular domains (residues 1 to 297) of hFcRn, cynoFcRn and mFcRn with a c-terminal poly-histidine tag were cloned respectively into pCDNA3.1 vectors. Then the vectors were co-transfected with a $\beta 2 \mathrm{M}$ expression vector into HEK293 6E cells using 293 fectine. After 72 $h$ of incubation with the transfection complex, the supernatants were harvested, and secreted proteins were purified using a HisTrap FF column on AKTA explorer (GE 
Healthcare). The fractions containing FcRn\& $\beta 2 \mathrm{M}$ heterodimer were pooled and bufferchanged to PBS.

For the production of scFv antibody fragments based on selected phage clone sequences, the genes were obtained by PCR using different sets of primers encompassing parts of the scFv gene and the restriction site EcoRI at the N-terminal or HindIII at the Cterminal. The PCR products were cloned into an expression vector containing a C-terminal FLAG and a poly-histidine tag. Then the vectors were transformed into HEK293 6E cells using 293fectin reagent. scFv fragments were purified from the supernatants using HisTrap FF column followed by affinity purification using anti-FLAG beads. The quality of the scFvs was determined by BCA and SDS-PAGE analysis.

Fusion proteins consisted of the modified GLP-1 sequence (no. 7-36 AA with mutations at $A 8 G, G 22 E, R 36 G)$ connected through a $(G 4 S)_{3}$ linker with the selected scFv sequences (FnAb8 or FnAb12) or an unrelated scFv sequence (scFv-n) were synthesized (Genscript) and cloned into the same expression vector as described above. The production and purification of the three fusion proteins were also similar. There were designated as G8, G12, and Gn respectively. The quality of the fusion proteins was determined by BCA and SDS-PAGE analysis.

\subsection{Cell lines}

For the characterization of antibody fragments binding to FcRn on cell membrane, we constructed an EGFP-hFcRn stable expression cell line 293T ${ }^{\text {EGFP-hFcRn }}$ and a control cell line $293 T^{\text {EGFP-HLA-A2 }}$ with stable expression of EGFP-HLA-A2 based on previously published protocols [48]. Specifically, to generate N-terminal EGFP-tagged construct, the pEGFP-N1 (Clontech, 6085-1) vector was modified by inserting the IL2 signal peptide sequence into the downstream of the CMV-IE promotor, between Nhel and Agel; to generate the hFcRn construct, the 5'-coding sequence (966bp, from AA24 to AA325) was PCR-amplified from hFcRn cDNA using forward (CCI GTA CAA GGC AGA AAG CCA CCT CTC CCT C, BsrGI site underlined) and reverse (TCT AGA CTA CTA CCT CAT CCT TCT CCA, Xbal site underlined) primers. This PCR product was digested with $\mathrm{BsrGl}$ and $\mathrm{Xbal}$, and inserted into the downstream of CMV-IE promoter, between BsrGI and Xbal restriction sites and in-frame with the EGFP coding sequence. The HLA-A construct was PCR-amplified from HLA-A2 CDNA

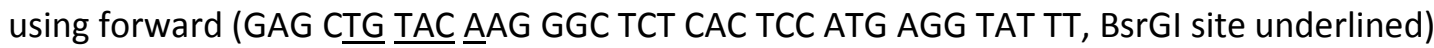
and reverse (GTC TAG ACT ATC ACA CTT TAC AAG CTG TGA GAG ACA C, Xbal site underlined) primers. The 1030bp PCR product was digested with $\mathrm{BsrGI}$ and $\mathrm{Xbal}$ and inserted into the pEGFP-N1 vector as described above. The EGFP-hFcRn and EGFP-HLA-A2 encoding vectors were respectively transfected into $293 \mathrm{~T}$ cells together with the $\beta 2 \mathrm{M}$ expressing plasmid using Lipofectamine2000. Stably transfected 293T cells were selected using $400 \mathrm{ug} / \mathrm{ml} \mathrm{G418}$ and $2.5 \mathrm{ug} / \mathrm{ml}$ Puromycin in $10 \%$ FBS-supplemented DMEM. The expression of hFcRn\& $\beta 2 \mathrm{M}$ and HLA-A2\& $32 \mathrm{M}$ heterodimers in their respective $293 \mathrm{~T}^{\text {EGFP-hFCRn }}$ and $293 \mathrm{~T}^{\text {EGFP-HLA-A2 }}$ cell lines were confirmed using confocal microscopy and FACS analysis with specific antibodies. 
The CRE-Luc/GLP-1R HEK293 cell line was obtained from HD Biosciences. HEK293 cells were co-transfected with GLP-1R expression plasmid and plasmid containing cAMP response element (CRE) fused with a Luciferase gene. The colonies expressing both human GLP-1 receptor and CRE-luciferase were selected using a luciferase assay system following treatment with $1 \mu \mathrm{M}$ of GLP-1 for $24 \mathrm{~h}$ in 96-well plates.

\subsection{Phage display library screening}

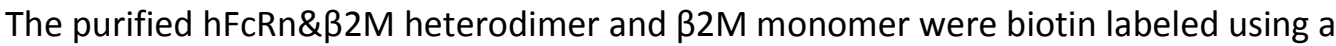
biotin protein labelling kit and attached to streptavidin-coupled Dynabeads. A naïve human scFv phage-display library (CP Co. Ltd., Shanghai) was used for subtractive panning against

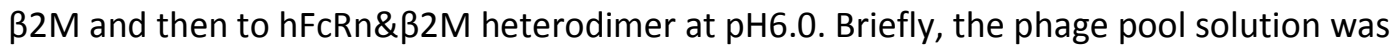
adjusted to $\mathrm{pH} 6.0$ and incubated firstly with $\beta 2 \mathrm{M}$ coated Dynabeads for $1 \mathrm{~h}$ at room

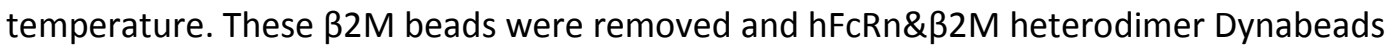
were added for panning at $\mathrm{pH} 6.0$ for another $1 \mathrm{~h}$ at room temperature. The resulted phage bound beads were then washed extensively with phosphate-buffered saline (PBS; pH6.0) containing $0.05 \%$ Tween-20 and finally PBS (pH7.4) to collect the released phage pool. The phage pool was amplified by infecting TG1 cells along with helper phage M13KO7 as described previously [49] and the panning was continued for 3 round. The phage clones selected were isolated and tested for binding and characterized by sequencing.

\subsection{ELISA analysis of $\mathrm{pH}$ dependent binding of selected phages to FcRn}

The various phage clones selected by screening were characterized for their $\mathrm{pH}$ dependent binding capabilities to FcRn using ELISA. Biotin labelled $\mathrm{hFcRn \& \beta 2M}$ or $\beta 2 \mathrm{M}$ were captured by streptavidin pre-coated ELISA plates and incubated at $37^{\circ} \mathrm{C}$ for 1 hour. The plates were then washed with pH6.0 PBST (0.05\% tween-20 in PBS) for three times, then 100ul of phage samples ( $\mathrm{pH}$ adjusted to $\mathrm{pH6.0}$ ) were added, and incubated for 1 hour at $37^{\circ} \mathrm{C}$. The plates were washed again with PBST at pH6.0 for 5 times. Then $100 \mu$ l of mouse anti-M13 phage antibody in PBS at pH6.0 was added to each well, and incubated for 1 hour at room temperature, followed by $100 \mu \mathrm{l} \mathrm{HRP-conjugated} \mathrm{anti-mouse} \mathrm{antibodies} \mathrm{with}$ washes between the steps, and detected with $100 \mu \mathrm{l}$ of 3,3',5,5'-Tetramethylbenzidine (TMB) substrate (Pierce) after 5 minutes development and $2 \mathrm{M} \mathrm{HCl}$ stop. All antibodies and buffers were adjusted to $\mathrm{pH6.0}$. The similar series of protocols were repeated using $\mathrm{pH} 7.4$ buffers to determine the $\mathrm{pH}$ dependent binding properties of the various phage clones. The optical absorbance at $450 \mathrm{~nm}$ were measured and reported.

2.6 Surface plasmon resonance (SPR) experiments

The various binding characteristics between FcRn and antibody fragments or fusions proteins were examined using surface plasmon resonance measurements. The Biacore T100 instrument (GE Healthcare) and the accompanied CM5 chip sets were used. 
The $\mathrm{CM} 5$ chips were coated with various FcRn\& $32 \mathrm{M}$ heterodimers (human, cynomolgus or mouse) or $\beta 2 \mathrm{M}$ as directed by the manufacturer (GE healthcare). The coupling was done by injecting $10 \mu \mathrm{g} / \mathrm{ml}$ of proteins in $10 \mathrm{mM}$ sodium acetate buffer pH5.0 followed by a blocking step using ethanolamine. For the SPR measurements, 200nM of scFv antibodies or GLP1-scFv fusion proteins were flowed over the prepared surface to record the binding process. Bindings at both $\mathrm{pH} 6.0$ and $\mathrm{pH} 7.4$ phosphate buffer solutions were measured.

For the binding kinetics analysis, FnAb-8 and FnAb-12 solutions at serially diluted concentrations ( $\mathrm{pH6.0:1-200nM;} \mathrm{pH7.4:} \mathrm{78-10000nM)} \mathrm{were} \mathrm{injected} \mathrm{with} \mathrm{a} \mathrm{flow} \mathrm{rate} \mathrm{of} 30$ $\mu \mathrm{l} / \mathrm{min}$ at $25^{\circ} \mathrm{C}$. The resulting sensorgrams were analyzed using the BIAevaluation 2.0.3 software based on the Langmuir 1:1 binding model.

The competitive binding properties of FnAb-8, FnAb-12 against hlgG or SA were analyzed by introducing $\mathrm{hFcRn \& \beta} 2 \mathrm{M}$ solution pre-mixed with the antibody fragments at a constant rate of $30 \mu \mathrm{l} / \mathrm{min}$ over immobilized human IgG or SA chips. A non-related scFv sample was also measured for comparison. The figures were plotted using Prism 5 (GraphPad Software, Inc.) and data analysis done using 2-way ANOVA.

For the binding of GLP1-scFv fusion proteins $\mathrm{G} 8$ and $\mathrm{G} 12$ with GLP-1R, the soluble GLP1R-Fc proteins were immobilized on CM5 chips. 200nM of G8, G12 and the original GLP1 peptide were injected. A non-related hlgG was used as Fc control.

2.7 FACS analysis of the various antibody fragments and fusion proteins binding to cell surface FcRns

The 293T ${ }^{\text {EGFP-hFCRn }}$ and $293 T^{\text {EGFP-HLA }}$ cell lines were established with stable expression and display of hFcRn\& $32 \mathrm{M}$ or HLA-A2\& $32 \mathrm{M}$ on cell surface. We used anti-hFcRn or anti-HLA-A2 antibodies to confirm the expression of surface maker. After 45 minutes incubation at $4{ }^{\circ} \mathrm{C}$, unbound antibodies were washed away and APC conjugated anti-mouse IgG was added for half an hour. Cells were washed, re-suspended in wash buffer plus 0.5\% BSA, and analyzed using a FACSCalibur (BD Biosciences).

The binding of hlgG and SA to $293 \mathrm{~T}^{\text {EGFP-hFCRn }}$ and $293 \mathrm{~T}^{\text {EGFP-HLA }}$ cells at various $\mathrm{pH}$ conditions were also examined. The cells were incubated with hlgG and SA pre-labeled with AF647 using a fluorescence labeling kit in pH6.0 or pH7.4 PBS buffers. They were then washed and resuspended in the same buffer plus $0.5 \% \mathrm{BSA}$ and analyzed using a FACSCalibur (BD Biosciences).

The bindings of the antibody fragments to $293 T^{\text {EGFP-hFCRn }}$ or $293 T^{\text {EGFP-HLA }}$ cells were analyzed similarly. Gradients of FnAb-8, FnAb-12, or an unrelated scFv were incubated with the cells in pH6.0 or pH7.4 PBS binding buffers respectively. Unbound antibodies were washed away with the same buffer. For detection, APC conjugated anti-Histag antibodies were added and incubated for half an hour. Cells were washed and resupended in the same 
buffer plus 0.5\% BSA and analyzed using a FACSCalibur (BD Biosciences). hIgG and SA labeled with AF647 was used as the positive control.

The competition between FnAb-8 or FnAb-12 and hlgG or SA binding to $293^{\text {EGFP-hFcRn }}$ cells was also examined. The fluorescence labeled hlgG ${ }^{\mathrm{AF} 647}$ and $\mathrm{SA}^{\mathrm{AF} 647}$ binding to $\mathrm{hFcRn}$ at different concentrations were evaluated and plotted using $293^{\text {EGFP-hFCRn }}$ cells. The $80 \% \mathrm{FcRn}$ bound concentration (EC80) of hlgG ${ }^{\mathrm{AF} 647}$ and SA ${ }^{\mathrm{AF} 647}, 1 \mu \mathrm{g} / \mathrm{ml}$ and $2.5 \mu \mathrm{g} / \mathrm{ml}$ were selected for scFv competition study. FnAb-8 or FnAb-12 were mixed at different ratios with IgG or SA (final concentration $1 \mu \mathrm{g} / \mathrm{ml}$ and $2.5 \mu \mathrm{g} / \mathrm{ml}$ respectively). The mixtures were added to $5 \times 10^{5}$ $293 T^{\text {EGFP-hFCRn }}$ cells and incubated for $30 \mathrm{~min}$ at $4^{\circ} \mathrm{C}$. They were then washed 3 times with pH6.0 buffer. Events were acquired on a FACSCalibur and the binding percentage of labeled hlgG or SA were recorded. All of the FACS data were analyzed with Flowjo software (V10.0.8).

2.8 In vitro characterization of GLP-1R agonist activities of GLP-1-scFv fusion protein G8 and G12

The CRE-Luc/GLP-1R HEK293 cell line was used for biological evaluation of FnAb-8, G8, FnAb-12, G12 and Gn. Briefly, the cells were seeded at a density of $5 \times 10^{4}$ cells/well in $96-$ well plates and grown overnight. Approximately 24 hours later, cells were treated with $10 \mu \mathrm{l}$ of FnAb-12, G8, FnAb-12, G12 or Gn solutions at various concentrations for 5 hours. They were then washed twice with PBS and lysed using $50 \mu$ l of $1 \times$ reporter lysis buffer. The luciferase activities were determined using an assay system in an E7031 plate reader (Promega). The activity-concentration data curves were plotted and EC50 values were calculated based on 4-parameters logistic Model using Prism 5 (GraphPad Software, Inc.).

2.9 In vivo characterization of GLP-1R agonist activities of GLP-1-scFv fusion protein G8, G12 and $G n$

Male C57BL/6 mice (7 weeks old) were purchased from JOINN Laboratory Inc (Suzhou, JS). All mice were maintained under a 12-hour light/dark cycle (lights on at 7 AM and off at 7 PM) with free access to food and water, except where noted. Animal handling and experiments were conducted in PegBio (Suzhou) according to the Principles of Laboratory Animal Care and the protocol was approved by the Experimental Animal Management Committee and Experimental Animal Ethics Committee of Shanghai JiaoTong University. The C57BL/6 mice were fed either standard rodent chow (SRC) or a high-fat diet (HFD, 45\% kcal from fat; Medicience Inc, Yangzhou, JS) for 18 weeks. Obese mice with $20 \%$ weight and $30 \%$ blood glucose increase than those SRC fed were randomized to 6 groups and given once subcutaneous (SC) injection of FnAb-8, FnAb-12, G8, G12, Gn or Exenatide (0.1mg/mouse). Using an Accu-Check Advantage glucometer (Roche), blood glucose were measured at each timepoint ( $0,2 \mathrm{~h}, 4 \mathrm{~h}, 6 \mathrm{~h}, 8 \mathrm{~h}$ or/and $10 \mathrm{~h}, 24 \mathrm{~h}, 32 \mathrm{~h}$ and $48 \mathrm{~h})$ and plotted against time point with Prism 5 (GraphPad Software, Inc.) and data analysis done using 2-way ANOVA. 
2.10 Pharmacokinetics studies in cynomolgus monkeys

The PK study protocol was approved by the Experimental Animal Management Committee and Experimental Animal Ethics Committee of Shanghai JiaoTong University and conducted at GuangXi Changchun Biotech Co., Ltd. Two healthy female cynomolgus monkeys (age 6.5-7 years; average weight $3.3 \mathrm{~kg}$ ) were admitted and acclimated in the study room for one week. They were given a single intravenous bolus injection of $1 \mathrm{mg} / \mathrm{kg}$ endotoxin-free biotin labeled FnAb-8 protein in PBS, followed by $1 \mathrm{ml}$ sterile PBS flush. Blood samples ( $2 \mathrm{ml}$ ) were taken at baseline (t0), 0.5, 6, 24, 48, 96, 240, 408, 576, 744, 1008 hours after injection. Blood was collected into EDTA containing tubes and centrifuged at $1,200 \mathrm{~g}$ at $4^{\circ} \mathrm{C}$ to separate plasma. Plasmas were stored at $-80^{\circ} \mathrm{C}$ until analysis. Quantitative ELISA assays were done using strepavidin pre-coated plates to determine the FnAb-8 concentration, using the material for injection as the standard. Data were plotted using ELISA concentration vs. time and analyzed based on the Linear Log Trapezoidal method, plasma (200-202) model (non-compartment model) using WinNonlin (Certara).

3. Results

\subsection{Screening and Identification of $\mathrm{pH}$-dependent $\mathrm{hFcRn}$ binders from a naïve human scFv phage library.}

The scFv phage library screening was carried out using soluble extracellular domain of FcRn. Since we are interested only in $\mathrm{pH}$ dependent binders, therefore we designed a binding at pH6.0 and eluting at pH7.4 panning strategy (Fig. 1A). In addition, because hFcRn

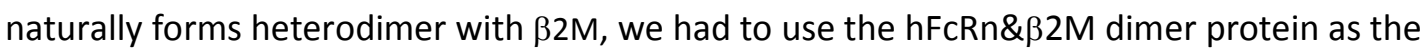
panning target and $\beta 2 \mathrm{M}$ as the control. In order to avoid interferences from $\beta 2 \mathrm{M}$ binders, we adopted an improved subtractive panning strategy, as shown in Fig. 1B. After three rounds of panning, totally 271 phage clones were identified. They were all tested for binding

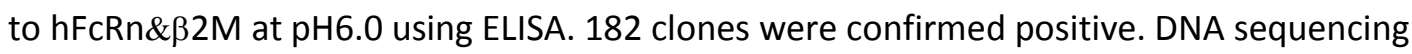
of the positive phages identified 16 clones with unique scFv gene sequences. Fig. $1 \mathrm{C}$ plotted

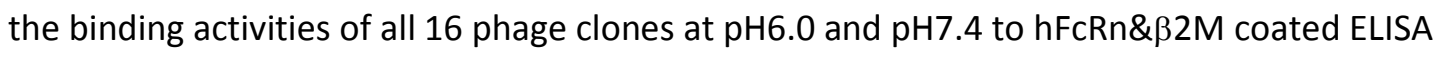
plates. Their bindings to $\beta 2 \mathrm{M}$ coated plates were also reported. 
A

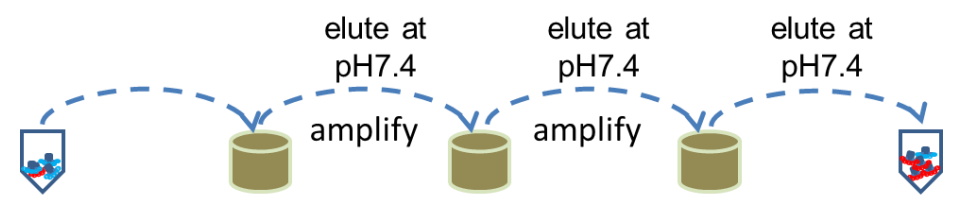

$\begin{array}{llll}\text { Phage Library } & \text { FcRn- } \beta 2 M & \text { FcRn- } \beta 2 M & \text { FcRn- } \beta 2 M\end{array}$ Enriched Phage

$$
1^{\text {st }} \text { round } \quad 2^{\text {nd }} \text { round } \quad 3^{\text {rd }} \text { round }
$$

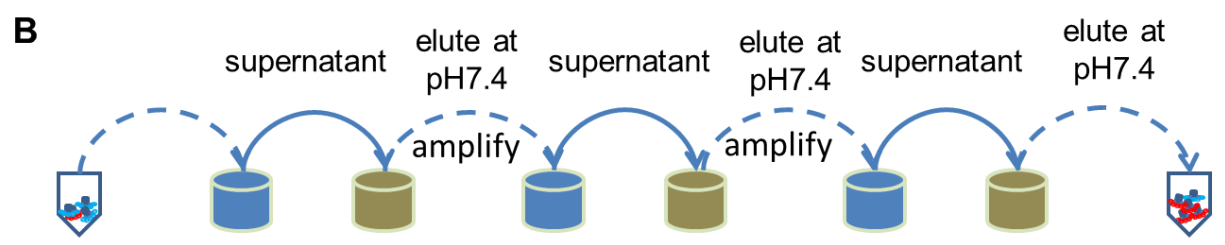

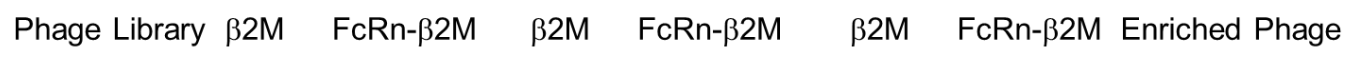

$$
1^{\text {st }} \text { round } \quad 2^{\text {nd }} \text { round } \quad 3^{\text {rd }} \text { round }
$$

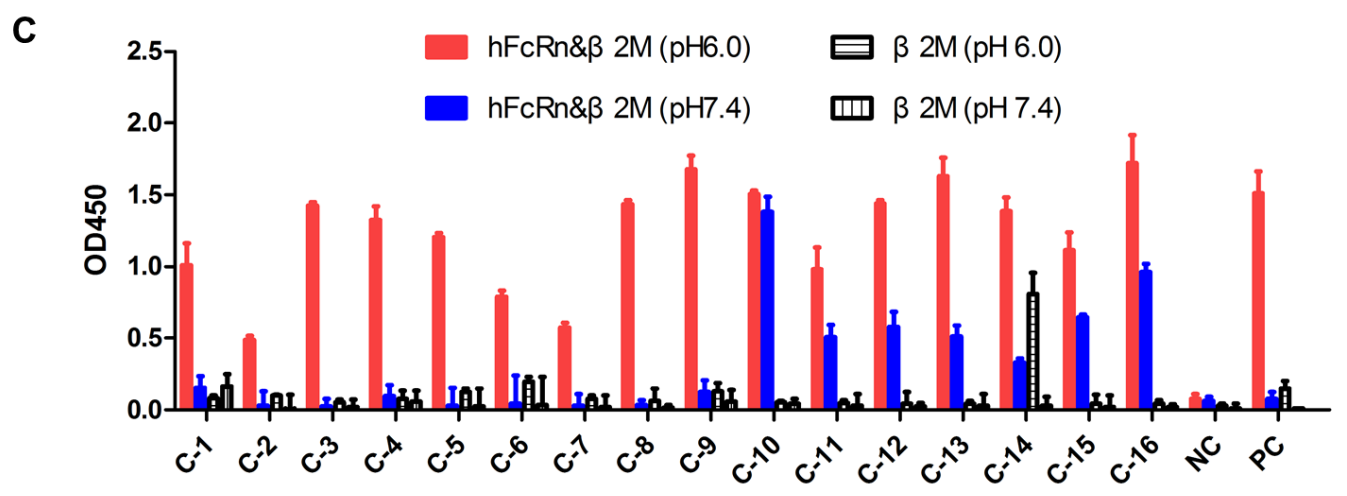

Fig.1. Phage library panning and binding to $\mathrm{hFcRn}$. (A) Direct panning strategy of phage library. (B) Subtractive panning strategy of phage library. (C) Binding of selected phages to hFcRn\& $\beta 2 \mathrm{M}$ or $\beta 2 \mathrm{M}$ coated on ELISA plates at acidic or neutral $\mathrm{pH}$. A non-relative phage clone was set as negative control (NC) and hlgG as positive control (PC). Bound phages were visualized using an HRP-conjugated anti-M13 antibody. The numbers given represent the mean of duplicates.

\subsection{Anti-hFcRn scFvs and GLP-1 fusion protein expression and characterizations of their binding properties}

The cDNA of 16 positive phage clones and one negative clone were amplified by PCR and inserted into expression vectors for scFv expression in mammalian cells. The expressed scFv fragment contained the antibody variable region followed by a C-terminal FLAG and then a poly-histidine tag. They were purified and designated as FnAb-1 to 16.

All these scFv fragments were tested for binding to $293 T^{\text {EGFP-hFcRn }}$ cells which overexpressed $\mathrm{hFcRn}$ on cell surfaces. Since the endosome targeting sequence in FcRn was excluded in the expression vector, the expressed EGFP-FcRns were confirmed to be on the 
cell surface with their respective antibodies (Fig. 2A). All the expressed scFvs were examined for their binding at both $\mathrm{pH} 6.0$ and pH7.4 buffers to $293 \mathrm{~T}^{\text {EGFP-hFCRn }}$ cells as well as $293^{\text {EGFP-HLA-A2 }}$ cells. The results were plotted in Fig. 2B with also the data from human IgG (PC) and an unrelated scFv control (NC). FnAb-8 and FnAb-12 were identified to have the best $\mathrm{pH}-$ preference at $\mathrm{pH} 6.0$ and selected as the candidates for further studies.

The detailed analysis of FnAb-8 and FnAb-12 binding to FcRn at pH6.0 were examined compared to those of IgG and SA. As shown in Fig. 2C, both FnAb-8 and FnAb-12 had better binding potency than hIgG and SA. In addition, the different binding profiles of FnAb-8 and FnAb-12 at pH6.0 and pH7.4, and with $293 \mathrm{~T}^{\text {EGFP-hFCRn }}$ cells as well as $293^{\text {EGFP-HLA-A2 }}$ cells were shown in Fig. 2D indicating clear pH dependency and FcRn specificity.

A

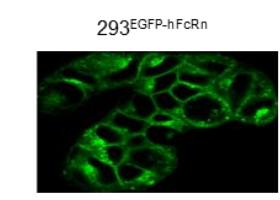

C

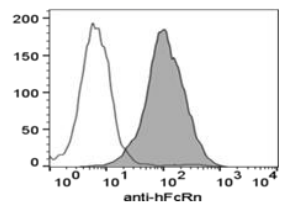

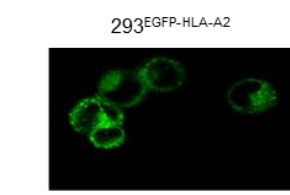

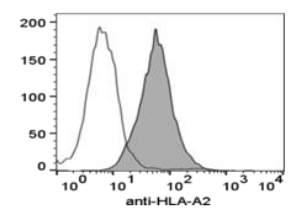

B

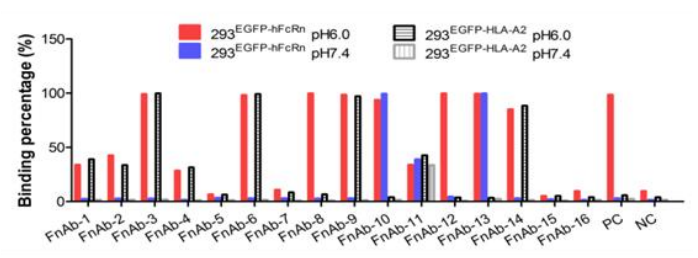

D

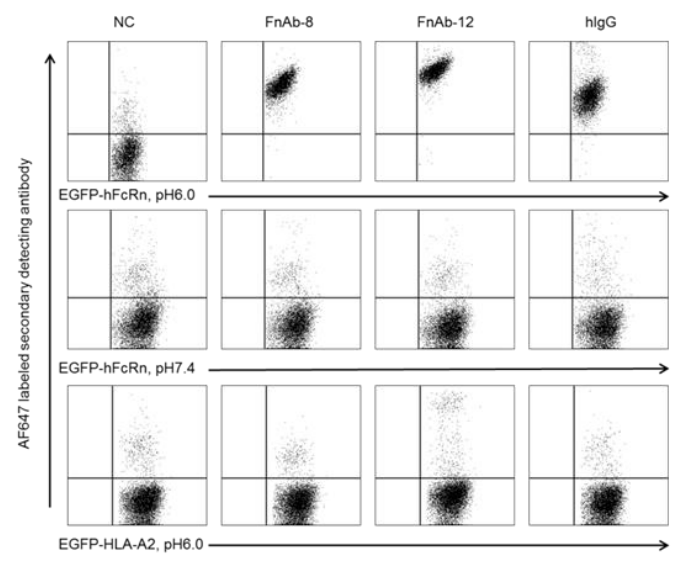

Fig. 2 Purified scFv antibodies binding to FcRn displaying cells. (A) 293T cells stably transfected with plasmid encoding the EGFP-fused hFcRn (left) or EGFP-fused HLA-A2 (right) were inspected by confocal microscopy. The $293 T^{\text {EGFP-hFcRn }}$ cells were stained with anti-hFcRn antibody (the gray filled, bottom-left) and the $293^{\text {EGFP-HLA-A2 }}$ cells were stained by anti-HLA-A2 antibody (the gray filled, bottom-right). (B) Purified scFv antibodies were examined for binding to $293^{\text {EGFP-hFCRn }}$ and $293^{\text {EGFP-HLA-A2 }}$ cells at $\mathrm{pH} 6.0$ and pH7.4. The binding percentage is the population of scFv antibodies binding to those EGFP gated cells. (C) The dose dependent binding analysis of FnAb-8 and FnAb-12 with hFcRn on cell surface compared to hlgG and SA. (D) Flow cytometry analysis of FnAb-8 and FnAb-12 binding to $293^{\text {EGFP-hFCRn }}$ cells. $293 T^{\text {EGFP- }}$ ${ }_{\text {hFCRn }}$ and $293 T^{\text {EGFP-HLA-A2 }}$ cells were incubated with unrelated scFv control (NC), FnAb-8, FnAb12 and hlgG at pH6.0 or pH7.4, followed by staining with secondary detecting antibody labeled with AF647 fluorescence. Data are representative of at least three experiments. 
The $\mathrm{pH}$ dependent bindings of FnAb-8 and FnAb-12 were further characterized by SPR. As shown in Figure 3, both had strong affinity towards FcRn at pH6.0. But at pH7.4, FnAb-8 had almost no binding. FnAb-12 and hIgG had similar binding at $\mathrm{pH} 7.4$, which was roughly one tenth of those at pH6.0 (Fig. 3A).

We also investigated the respective binding affinities of FnAb-8 and FnAb-12 to human FcRn (hFcRn), cynomolgus FcRn (cynoFcRn) and mouse FcRn (mFcRn). As shown in Fig. 3B, since $h F c R n$ and cynoFcRn are highly homologous, FnAb-8 and FnAb-12 bound both with similar kinetics. The $\mathrm{mFcRn}$ is quite different, FnAb-8 bound with very low affinity and FnAb12 with almost no affinity. The binding curves were fitted to a simple 1:1 Langmuir binding model and the estimate KD values were listed in Fig. 3C.

A

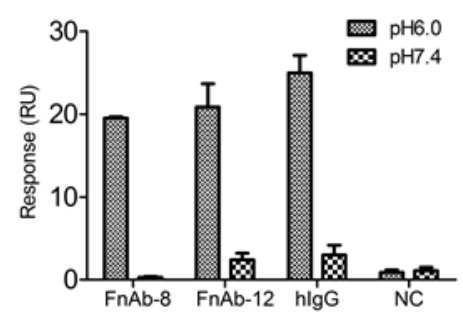

B
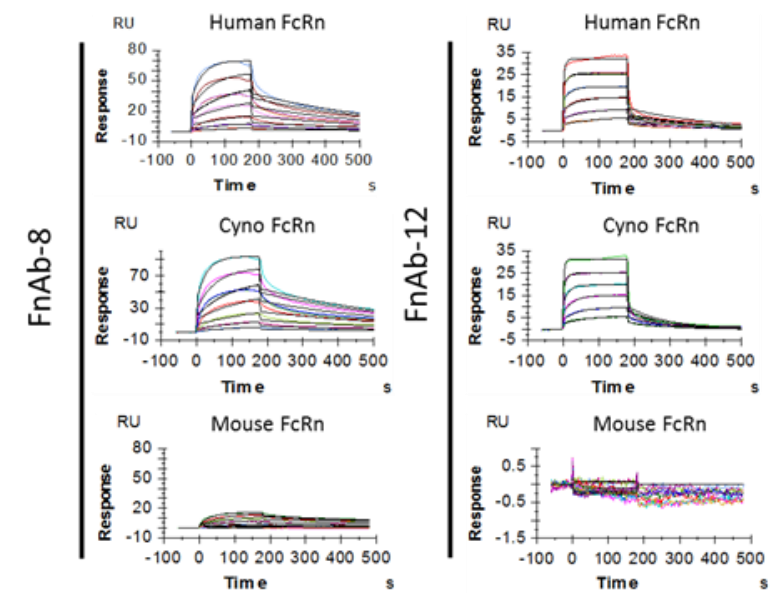

C

Binding kinetics of scFvs

\begin{tabular}{ccccc}
\hline Analyte & Ligand & $\mathbf{k}_{\mathbf{a}}\left(\mathbf{M}^{-1} \mathbf{s}^{-1}\right)$ & $\mathbf{k}_{\mathrm{d}}\left(\mathbf{s}^{-1}\right)$ & $\mathbf{K}_{\mathrm{D}}(\mathbf{M})$ \\
\hline FnAb-8 & hFcRn & $6.14 \mathrm{E}+05$ & $2.65 \mathrm{E}-03$ & $4.32 \mathrm{E}-09$ \\
FnAb-8 & cyFcRn & $9.34 \mathrm{E}+05$ & $4.16 \mathrm{E}-03$ & $4.45 \mathrm{E}-09$ \\
FnAb-12 & hFcRn & $2.37 \mathrm{E}+06$ & $1.02 \mathrm{E}-01$ & $4.32 \mathrm{E}-08$ \\
FnAb-12 & cyFcRn & $1.06 \mathrm{E}+06$ & $1.55 \mathrm{E}-01$ & $1.46 \mathrm{E}-07$ \\
\hline
\end{tabular}

Fig. 3. Binding of scFvs to FcRn examined by SPR. (A) Soluble hFcRn were immobilized on $\mathrm{CM} 5$ chip and binding of scFvs and hlgG at pH6.0 and pH7.4 were plotted. (B) Kinetics study 
of purified scFv fragments to human, cyno and mouse FcRn at pH6.0. (C) The binding parameters of scFvs to human and cyno FcRn at pH6.0.

Fusion proteins containing a mutated GLP-1 sequence connected through a (G4S) $)_{3}$ linker with the scFv fragments were expressed in 293E cells, purified, and characterized using SDSPAGE (Fig. 4A). Both G8 (GLP-1-FnAb8) and G12 (GLP-1-FnAb-12) were studied by SPR for their binding to $h F c R n$ as well as GLP-1R-Fc using SPR. The addition of GLP-1 sequence to the scFvs didn't change their FcRn binding capabilities and pH dependency at all (Fig. 4B). The fusion proteins also retained their binding to GLP1R-Fc (Fig. 4C).
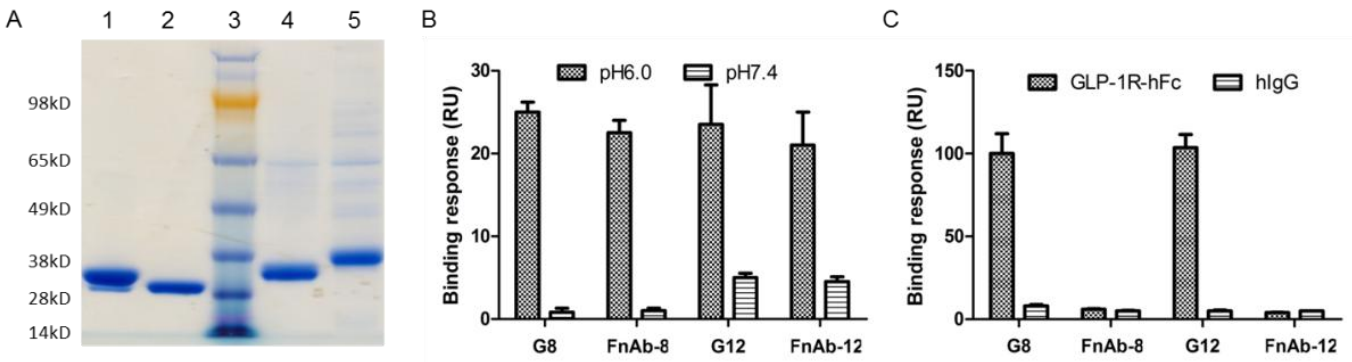

Fig. 4. Mammalian cell production of scFvs and GLP-1 fusion proteins and their binding to hFcRn and GLP-1R. (A) FnAb-8, FnAb-12, G8 and G12 were produced in 293E cell and purified and analyzed by 4-12\% SDS-PAGE. Lane 1: G8, Lane 2: FnAb-8, Lane 3: molecular weight (MW) markers, Lane 4: FnAb-12, Lane 5: G12. (B) Binding to soluble hFcRn by SPR. (C) Binding to soluble GLP-1R-hFc by SPR. Injections were done at pH6.0 at $25{ }^{\circ} \mathrm{C}$ with a flow rate of $30 \mu \mathrm{l} / \mathrm{min} . \mathrm{n}=3-4$.

\subsection{The interference of $\operatorname{IgG} / \mathrm{SA}$ binding to scFv fragment interactions with FcRn}

Since both endogenous IgG and SA can bind to FcRn although at different binding sites, we have to investigate the binding of scFvs to hFcRn under the context of hlgG or SA binding as well. We immobilized hlgG and SA on CM5 sensor chips and injected soluble hFcRn premixed with anti-hFcRn scFvs at pH6.0. As shown in Fig. 5A, SA had no effect whatsoever to scFv-FcRn interactions, suggesting SA bind at a region distinct from scFvs or has a much lower affinity to FcRn. FnAb-8 interfered with IgG binding to FcRn slightly, suggesting there may be some binding site overlapping. FnAb-12, on the other hand, was shown to result in even higher signals based on FcRn binding to IgG. It may indicate that FcRn can bind to IgG and FnAb-12 simultaneously or the binding of FnAb-12 could even induce FcRn conformation change to facilitate IgG binding.

Similarly, the binding of FnAb-8 and FnAb-12 to $293^{\text {hFcRn-GFP }}$ cells were also examined in the presence of IgG or SA. The concentrations of IgG and SA in the studies were set at 1 $\mu \mathrm{g} / \mathrm{ml} \mathrm{hlgG}^{\mathrm{AF} 647}$ or $2.5 \mu \mathrm{g} / \mathrm{ml} \mathrm{SA}^{\mathrm{AF647}}$ respectively when about $80 \%$ of the cell surface FcRns were estimated to be occupied. The FACS analysis confirmed the interference of scFv antibodies to hlgG and SA interaction with hFcRn on $293 T^{\text {EGFP-hFcRn }}$ cells. The results also 
demonstrated a different binding pattern of FnAb-8 and FnAb-12 (Fig. 5B), confirming the SPR assay data.

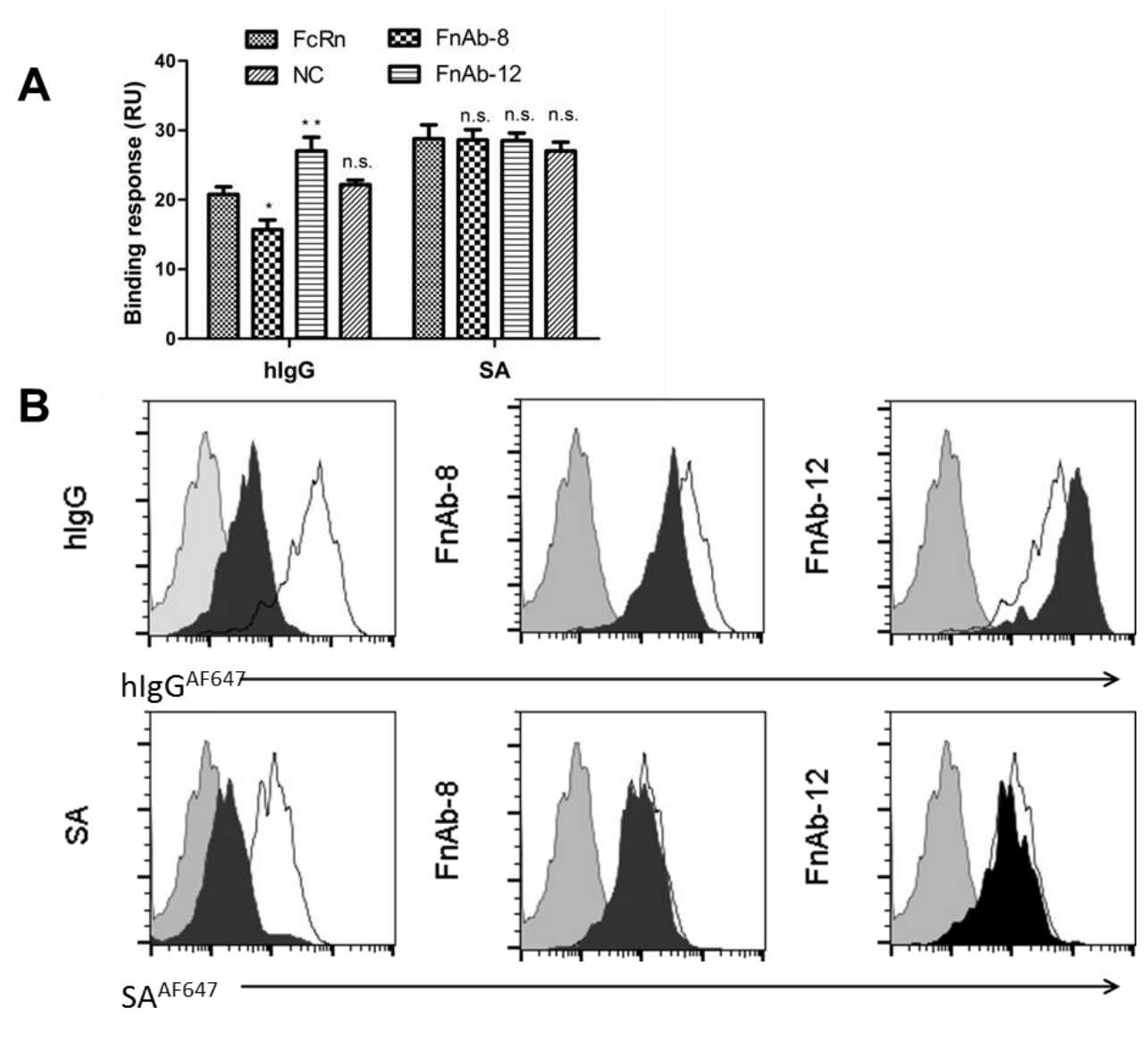

Fig.5 Interference of IgG/SA binding to scFv fragment interactions with FcRn. (A) SPR signals based on hFcRN binding to immobilized hlgG or SA chips affected by anti-hFcRn scFvs. Injections were done at $\mathrm{pH} 6.0$ at $25^{\circ} \mathrm{C}$ with a flow rate of $30 \mu \mathrm{l} / \mathrm{min} . \mathrm{n}=3$. All data were reported as mean \pm s.d. and analyzed using two-way ANOVA, n.s.,P>0.05; $*, \mathrm{P}<0.05 ; * *, \mathrm{P}<0.01$. (B) Binding of fluoresce labeled $\mathrm{hlgG}^{\mathrm{AF} 647}$ or $\mathrm{SA}^{\mathrm{AF} 647}$ to $\mathrm{hFCRn}$ expressing cells affected by anti-hFcRn scFvs or unlabeled IgG/SA. The gray filled peaks are cells without binding. The blank peaks are hlgG ${ }^{\mathrm{AF} 647}$ or $\mathrm{SA}^{\mathrm{AF647}}$ bound cells at $1 \mu \mathrm{g} / \mathrm{ml}$ $\mathrm{hlgG}^{\mathrm{AF} 647}$ or $2.5 \mu \mathrm{g} / \mathrm{ml} \mathrm{SA}^{\mathrm{AF} 647}$ respectively. The black filled peaks are $\mathrm{hlgG}^{\mathrm{AF} 647}$ or SA ${ }^{\mathrm{AF} 647}$ bound cells in the presence of unlabeled IgG/SA, FnAb-8, and FnAb-12. Data were representative at least two experiments.

\subsection{In-vitro and in-vivo activities of GLP1-scFv fusion proteins}

The in vitro activities of GLP-1-scFv fusion proteins in parallel with their parental scFvs was examined in CRE-luc/GLP-1R co-transfected HEK293 cells (Fig. 6A). The EC50 of both G8 and $\mathrm{G} 12$ was found to be around $0.5 \mathrm{nM}$, which is comparable to GLP-1 analogs reported 
using similar assays $[50,51]$. In contrast, the parental scFvs FnAb-8 and FnAb-12 showed no agonistic effect to GLP-1R.

We next examined whether G8, G12 and Gn can in fact reduce glucose excursion in mice with high fat diet induced obesity and diabetes. After 18 weeks of feeding, the high fat diet fed (HFD) mice were over-weight and blood glucose concentrations 30\% above normal level. A single bolus injection of both $\mathrm{G} 8, \mathrm{G} 12$ as well as $\mathrm{Gn}$ resulted in significantly reduced blood glucose concentrations for several hours after injection (Fig.6B-D). Figure 6B indicated that such effects were due to the GLP-1 analogue fusion, because both FnAb-8 and FnAb-12 had no activity. Figure $6 \mathrm{C}$ showed that the duration of activities by G8 and $\mathrm{G} 12$ were both significantly longer than the GLP-1 analog Exenatide $(P<0.01)$. Most importantly, as shown in Figure 6D, the effects of G8 and G12 also lasted slightly longer than Gn which had roughly the same molecular weight but no interaction with mouse FcRn at all $(p<0.01)$. Such differences were thought to be due to the residue binding affinities of FnAb-8 and FnAb-12 with mouse FcRn, although they may be much lower than their affinities towards human FcRn.
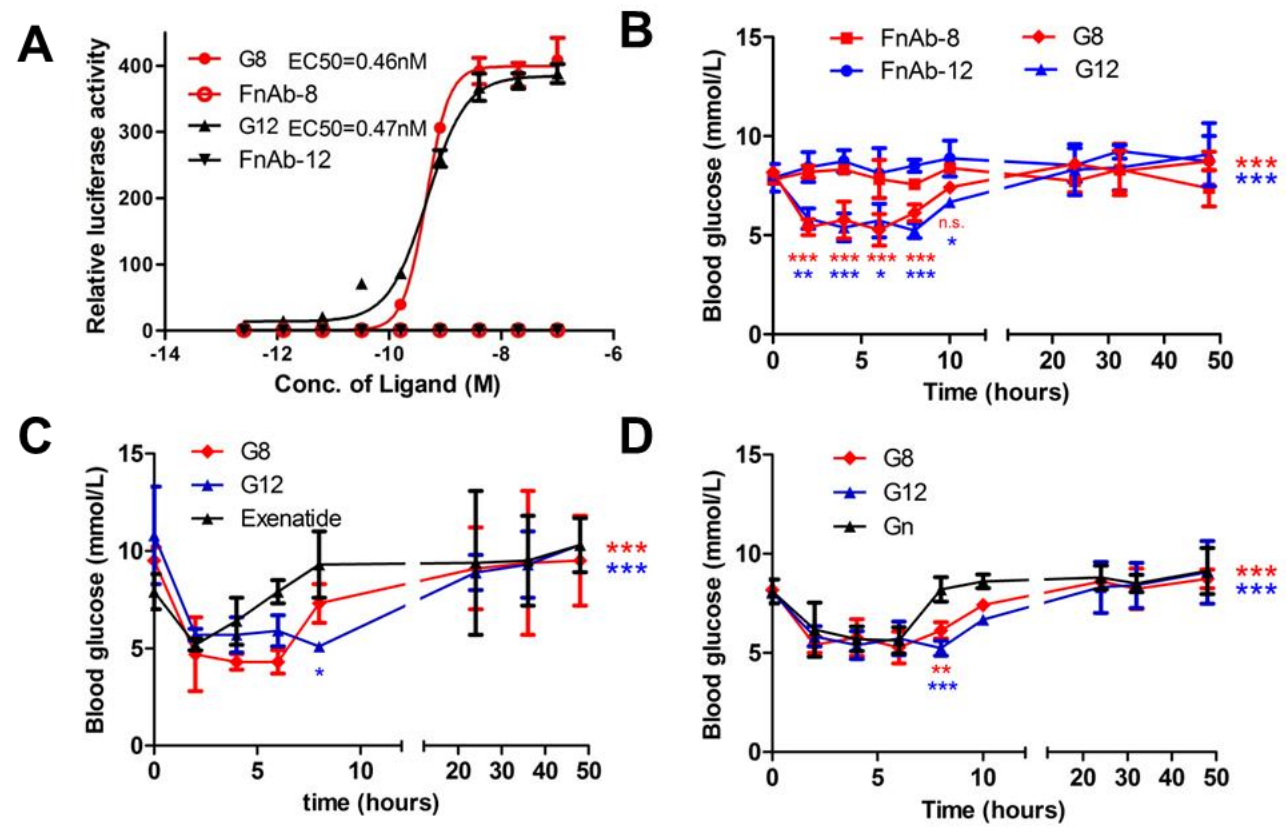

Fig. 6 Biological activity of scFv-GLP-1 fusion proteins in-vitro and in-vivo. (A) Evaluation of FnAb-8, G8, FnAb-12 and G12 activities as human GLP-1 receptor agonists using a luciferase report assay in a human GLP-1 receptor/CRE-Luciferase-co-expressed HEK293 cell line. (B) FnAb-8 (red square), G8 (red diamond), FnAb-12 (blue diamond) and G12 (blue triangle) activities for lowering blood glucose levels of HFD mice, as competed to FnAb-8 (red square) and FnAb-12 (Blue dot) respectively. (C) G8 (Red line) and G12 (Blue line) activities for lowering blood glucose levels of HFD mice, as compared to that of Exenatide (black line). (D) G8 (Red line) and G12 (Blue line) activities for lowering blood glucose levels 
of HFD mice, as compared to Gn (black line). All of the data are presented as means \pm s.d.

$\mathrm{n}=3$; Analyzed using two-way ANOVA. n.s., $\mathrm{P}>0.05 ;{ }^{*}, \mathrm{p}<0.05 ;{ }^{* *}, \mathrm{p}<0.01 ;{ }^{* * *}, \mathrm{p}<0.001$. The red stars at each time point indicated the statistical analysis between data from $\mathrm{G} 8$ and Exenatide/Gn. The blue stars at each time point indicated the statistical analysis between data from G12 and Exenatide/Gn and represented the significance between G8/G12 and exenatide or $\mathrm{Gn}$ separately. The red and blue stars at the end of the curves indicate the significance of difference of the whole time.

\subsection{In vivo Pharmacokinetics study of FnAb-8 in cynomolgus monkeys}

Since cyno FcRn is highly homologous to human FcRn, we studied the PK properties of FnAb-8 in two cynomolgus macaques. FnAb-8 was administered as a single bolus injection. Its plasma-concentration following the injection was monitored for 1000 hours and plotted in Fig. 7A. There were some discrepancies between the two data sets from two animals, we analyzed them individually and reported the calculated PK parameters in Fig. 7B.

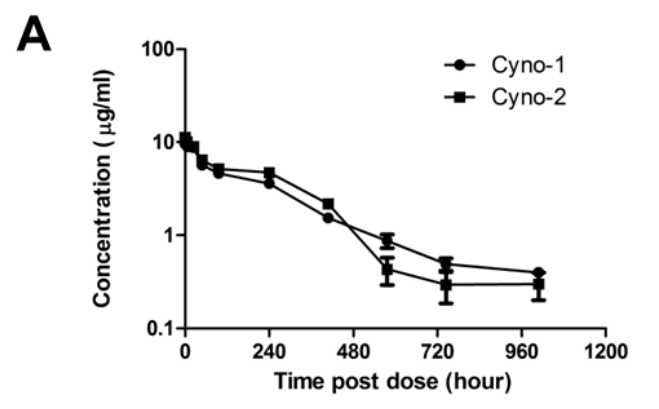

B

Pharmacokinetic study of FnAb-8 in cynomolgus macaque

\begin{tabular}{ccccc}
\hline ID & $\begin{array}{c}\beta \text { phase } \\
\mathrm{T}_{\mathbf{1 / 2}} \text { (hour) }\end{array}$ & $\begin{array}{c}\text { AUC }_{\text {inf }} \\
\text { (ug }^{*} \text { hour/ml) }\end{array}$ & $\begin{array}{c}\text { Cl_F } \\
\text { (ml/hour/kg) }\end{array}$ & $\begin{array}{c}\text { MRT } \\
\text { (hour) }\end{array}$ \\
\hline Cyno-1 & 204 & 2084 & 0.48 & 273 \\
Cyno-2 & 98 & 2200 & 0.45 & 204 \\
\hline
\end{tabular}

$\beta$ phase $T_{1 / 2}$ ( hour), elimination half-life; $A U C$, area under the plasma concentration curve; $C L$, total body clearance; MRT, mean residence time.

Fig. 7 Pharmacokinetics study of FnAb-8 in cynomolgus monkeys . (A) Measurements of FnAb-8 blood concentration over time. (B) Analysis of in vivo PK data.

4. Discussion

A major challenge for the therapeutic use of many peptides and proteins is their short blood half-life. Their fast clearance from circulation is mainly based on two mechanisms: 
renal filtration and lysosome degradation. There are in general two strategies to address these problems for prolongation of the drug's half-life: (i) to increase molecular size and its hydrodynamic volume by coupling polymers, carbohydrates or other proteins [52-54] and (ii) to take advantage of the recycling mechanism mediated by FcRn and avoid rapid degradation [55-57]. Both strategies have been pursued extensively and proven to be successful. Especially based on the later strategy, the Fc part of IgG, SA and some Fc, SA binding peptides/proteins had been developed and used to fuse with biotherapeutics for longer half-life in vivo. A comprehensive review by Sockolosky \& Szoka was published recently [58]. FcRn was regarded as an important target for drug delivery, with applications going beyond half-life extension.

There are some limitations using the endogenous Fc fragment or SA as the carrier for other drugs. One concern is that Fc has other targets besides FcRn that can lead to other pharmacological effects [47]. Also, both are quite big and add to the manufacture costs. So it is highly desirable to develop new structures targeting to FcRn that can achieve even better pharmacokinetic performance in clinical applications. Ying et al. reported a short FcRn binding motif derived from Fc $\mathrm{CH} 3$ domain that exhibited improved FcRn binding [33]. Seijsing et al. described a detailed study using an Affibody library to screen for small affinity proteins (consisting of only 58 amino acids) [34]. Sockolosky et al. used a short peptide sequence that could compete with human IgG for FcRn [35]. Andersen et al. identified a nanobody from a variable-domain repertoire library isolated from a llama immunized with human FcRn [36]. Nixon et al. selected potent inhibitors of IgG binding to human-FcRn at pH 7.4 from a phage library [45].

While most studies have done comprehensive characterizations of FcRn binding in various in vitro and cell models, in vivo studies examining the circulation half-lives have been hard to compare because of different species preferences and model selections. Ying et al. described an FcRn binding motif derived from the $\mathrm{Fc} \mathrm{CH} 3$ domain which had an elimination half-life at about 44.1 hours in cynomolgus macaques [33]. The $\mathrm{pH}$-independent FcRn antibodies selected by Nixon et al. had only 5 to 13 hrs half-life in cynomolgus monkey [45]. Compared to these numbers, our preliminary data as shown in Figure 7 seemed to be superior.

Indeed, we initiated this study with the hypothesis that ScFv antibodies that specifically recognize hFcRn with high affinity and superior $\mathrm{pH}$ preference at acidic $\mathrm{pH}$ may be optimal as carrier scaffolds for biopharmaceutics. The IgG Fc and SA interactions with FcRn at pH6 had been shown to have KDs in the hundreds nM range $[17,20]$. But since the IgG binding to FcRn was found to have a 1:2 stoichiometry $[66,67]$, the apparent binding affinity between IgG and FcRn would be higher than that of SA. As shown in Figure $2 \mathrm{C}$, our two scFvs had higher affinities than both IgG and SA, although their bindings should be based on a 1:1 stoichiometry. The KD value was estimated to be in the $5-50 \mathrm{nM}$ range at $\mathrm{pH} 6.0$, similar to the $1 \mathrm{G} 3$ antibody previously reported [59]. 
But based on the FcRn mediated IgG/SA recycling mechanism, the $\mathrm{pH}$ depend binding property may be even more important than the binding affinity per se [44, 46]. Although FcRn can be found both at the cell surface and in intracellular compartments, studies based on FcRn knockout mice suggested that it's the interactions at acidic $\mathrm{pH}$ that determines the recycling activities [27]. In endothelial and other cell types, FcRn mainly resides in the endosomal compartments. FcRn binds to IgG and SA that were nonspecifically endocytosed and salvages them from lysosomal degradation. So all the screening assays as well as the most initial characterizations were done at pH6.0. But we also incorporated a special elusion step at pH7.4 in the phage screening scheme (Fig. 1). It is based on the biological fact that the ligand-FcRn complex would have to dissociate after being transported back to the plasma membrane via recycling endosomes [24-28]. In fact, it's the differences between bindings at these two pHs that was considered as the major screening criteria for the selection of final candidates.

Furthermore, our screening scheme also included a subtractive panning strategy which was important for the successful panning (Fig. 1). Since FcRn is stable in the heterodimer form with $\beta 2 \mathrm{~m}$, we found in preliminary studies that there might be many hits bound to $\beta 2 \mathrm{~m}$. The subtractive panning step was used to successfully rule out those binders. In later studies when we verify the selected phages or scFvs, we always included a HLA control which is also in a heterodimer form with $\beta 2 \mathrm{~m}$.

With all these considerations, the screening effort was quite successful. FnAb-8 and FnAb-12 were selected as the final candidates. They were validated as $h F c R n$ specific binders with $\mathrm{pH}$ dependency. Both have significantly improved hFcRn binding affinity (about 10 to 100 -folds higher than hlgG) at pH6.0 but maintained weak binding at neutral $\mathrm{pH}$. However, unlike what was reported by Seijsing et al., FnAb-8 and FnAb-12 had narrower specificity towards only human and cynomolgus FcRn, with only minimum affinity towards mouse FcRns. It may due to different binding epitopes in $\mathrm{hFcRn}$ and $\mathrm{mFcRn}$, just like the dramatic cross-species differences in IgG and albumin binding [20]. Therefore, we had to examine the PK profile only in primate models. The calculated elimination half-life was between 100-200 hours, which is about two times longer than the 44.1 hours mean number reported by Ying et al [33]. It is very encouraging considering the overall small molecular weight of scFvs. Other ScFv or scFv fusion proteins usually had in vivo circulation half-lives of minutes to hours $[60,61]$ without the Fc domain and the recycling mechanism. Clearly, the binding of FnAb-8 and FnAb-12 to FcRn at pH6.0 made huge differences. They can be highly valuable as carriers to help prolonging the serum half-life of other therapeutic proteins.

Finally, we explored the activities of a peptide fusion protein with the selected scFvs. GLP-1 is a typical peptide hormone which is highly potent but not suitable for therapy due to its very short circulation life [62]. Native GLP-1 is rapidly inactivated with a half-life of 1-2 min [63]. GLP-1 (7-36) was the active metabolite and several amino acid substitutions (A8G, 
G22E, R36G) were suggested to render the molecule resistant to DPP-4 and chemically more stable. A fusion protein containing a modified GLP-1 connected to a SA has been approved for clinical use with human half-life around 5 days $[64,65]$. We constructed $G 8$ and G12 based on the FnAb-8 and FnAb-12 sequence and examined their activities in vitro and in vivo. In addition, the fusion of an unrelated ScFv with GLP-1 designated as Gn was also tested for comparison. As shown in Fig. 4, G8 and G12 retained their affinity and pHdependent binding to FcRn. They were all active in cell assays demonstrating GLP-1R agonist activities (Figure 6A). In HFD mouse studies, G8, G12, as well as Gn were able to reduce blood glucose levels with similar potency as the GLP-1 analogue peptide Exenatide. Their activity durations were also longer than that of Exenatide because of the higher MWs (Fig. 6C, 6D). However, as shown in Figure 6D, G8 and G12's activities lasted slightly (yet significantly) longer than that of $\mathrm{Gn}$, suggesting there were still residue interactions between $\mathrm{G} 8$ and $\mathrm{G} 12$ with mouse FcRn, despite that both FnAb-8 and FnAb-12 were selected for human FcRn and only very poor binding with mouse FcRn might exist.

The data shown in Figure 7 was based on a preliminary evaluation of the half-life extension effects of FnAb-8 based on $\mathrm{pH}$ dependent binding to FcRn. The results were highly encouraging as discussed earlier. Further studies examining the activities and PK properties of fusion proteins such as $\mathrm{G} 8$ in primate models would be necessary to fully evaluate the clinical potentials of the ScFv scaffolds developed in this study. .

5. Conclusion

In this study, we identified two candidate scFv structures that can bind to human FcRn with great specificity, high affinity at $\mathrm{pH} 6.0$, and low to almost no binding at $\mathrm{pH} 7.4$. They were shown to have extended circulation half-lives in cynomolgus monkeys. They can be used as a carrier protein to be fuse with the therapeutic peptide GLP-1 to improve its stability and activity duration in vivo.

Acknowlegements:

We thank the financial supports from NSFChina grant No.81273465 and the Chinese Ministry of Sci. \& Tech grant No. 2014 AA020707.

\section{Reference:}

[1] C.L.A. R.P. Junghans, The protection receptor for IgG catabolism is the beta2-microglobulincontaining neonatal intestinal transport receptor, Proc. Natl. Acad. Sci. 93 (1996) 55125516.

[2] C. Chaudhury, S. Mehnaz, J.M. Robinson, W.L. Hayton, D.K. Pearl, D.C. Roopenian, et al., The major histocompatibility complex-related Fc receptor for IgG (FcRn) binds albumin and prolongs its lifespan., J. Exp. Med. 197 (2003) 315-322. doi:10.1084/jem.20021829. 
[3] D.C. Roopenian, S. Akilesh, FcRn: the neonatal Fc receptor comes of age. Nat. Rev. Immunol. 7 (2007) 715-725. doi:10.1038/nri2155.

[4] R. Rodewald, pH-dependent binding of immunoglobulins to intestinal cells of the neonatal rat. J. Cell Biol. 71 (1976) 666-669. doi:10.1083/jcb.71.2.666.

[5] N.E. Simister, A.R. Rees, Isolation and characterization of an Fc receptor from neonatal rat small intestine. Eur. J. Immunol. 15 (1985) 733-738. doi:10.1002/eji.1830150718.

[6] P.J. Hornby, P.R. Cooper, C. Kliwinski, E. Ragwan, J.R. Mabus, B. Harman, et al., Human and Non-Human Primate Intestinal FcRn Expression and Immunoglobulin G Transcytosis, Pharm. Res. 31 (2014) 908-922. doi:10.1007/s11095-013-1212-3.

[7] F. Antohe, L. Rădulescu, A. Gafencu, V. Ghe, M. Simionescu, Expression of functionally active FcRn and the differentiated bidirectional transport of IgG in human placental endothelial cells, Hum. Immunol. 62 (2001) 93-105. doi:10.1016/S0198-8859(00)00244-5.

[8] U. Shah, B.L. Dickinson, R.S. Blumberg, N.E. Simister, W.I. Lencer, W.A. Walker, Distribution of the IgG Fc receptor, FcRn, in the human fetal intestine, Pediatr. Res. 53 (2003) 295-301. doi:10.1203/01.PDR.0000047663.81816.E3.

[9] Y. Ben Suleiman, M. Yoshida, S. Nishiumi, H. Tanaka, T. Mimura, K. Nobutani, et al., Neonatal Fc receptor for IgG (FcRn) expressed in the gastric epithelium regulates bacterial infection in mice, Mucosal Immunol. 5 (2012) 87-98. doi:10.1038/mi.2011.53.

[10] S. Akilesh, G.J. Christianson, D.C. Roopenian, A.S. Shaw, Neonatal FcR expression in bone marrow-derived cells functions to protect serum IgG from catabolism. J. Immunol. 179 (2007) 4580-4588. doi:179/7/4580 [pii].

[11] B.R. Zhu X, Meng G, Dickinson BL, Li X, Mizoguchi E, Miao L, Wang Y, Robert C, Wu B, Smith $P D$, Lencer $\mathrm{WI}, \mathrm{MHC}$ class I-related neonatal Fc receptor for IgG is functionally expressed in monocytes, intestinal macrophages, and dendritic cells. J Immunol. 166 (2001) 3266-3276. doi:10.1055/s-0029-1237430.Imprinting.

[12] S. Akilesh, T.B. Huber, H. Wu, G. Wang, B. Hartleben, J.B. Kopp, et al., Podocytes use FcRn to clear IgG from the glomerular basement membrane., Proc. Natl. Acad. Sci. U. S. A. 105 (2008) 967-972. doi:10.1073/pnas.0711515105.

[13] K. Cauza, G. Hinterhuber, R. Dingelmaier-Hovorka, K. Brugger, G. Klosner, R. Horvat, et al., Expression of FcRn, the MHC class I-related receptor for IgG, in human keratinocytes, J. Invest. Dermatol. 124 (2005) 132-139. doi:10.1111/j.0022-202X.2004.23542.x.

[14] F. Schlachetzki, C. Zhu, W.M. Pardridge, Expression of the neonatal Fc receptor ( FcRn ) at the blood - brain barrier, J. Neurochem. 81 (2002) 203-206. doi:10.1046/j.14714159.2002.00840.x

[15] N.E. Simister, K.E. Mostov. An Fc receptor structurally related to MHC class I antigens. Nature. 337(1989) 184-187. doi:10.1038/337184a0

[16] W.P. Burmeister, L.N. Gastinel, N.E. Simister, M.L. Blum, P.J. Bjorkman. Crystal structure at $2.2 \AA$ resolution of the MHC-related neonatal Fc receptor. Nature.372 (1994) 336-343. doi: $10.1038 / 372336 \mathrm{a} 0$

[17] T. Schlothauer, P. Rueger, J.O. Stracke, H. Hertenberger, F. Fingas, L. Kling, et al., Analytical FcRn affinity chromatography for functional characterization of monoclonal antibodies, MAbs. 5 (2013) 576-586. 
[18] M. Raghavan, M.Y. Chen, L.N. Gastinel, P.J. Bjorkman, Investigation of the interaction between the class I MHC-related Fc receptor and its immunoglobulin G ligand., Immunity. 1 (1994) 303-315. doi:10.1016/1074-7613(94)90082-5.

[19] M. Raghavan, L.N. Gastinel, P.J. Bjorkman. The class I major histocompatibility complex related Fc receptor shows $\mathrm{pH}$-dependent stability differences correlating with immunoglobulin binding and release. Biochemistry 32 (1993) 8654-8660.

[20] J.T. Andersen, M.B. Daba, G. Berntzen, T.E. Michaelsen, I. Sandlie, Cross-species binding analyses of mouse and human neonatal Fc receptor show dramatic differences in immunoglobulin G and albumin binding, J. Biol. Chem. 285 (2010) 4826-4836.

[21] C. Chaudhury, C.L. Brooks, D.C. Carter, J.M. Robinson, C.L. Anderson, Albumin Binding to FcRn : Distinct from the FcRn - IgG Interaction, Biochemistry. 45 (2006) 4983-4990. doi:10.1021/bi052628y.

[22] D.E. Vaughn, C.M. Milburn, D.M. Penny, W.L. Martin, J.L. Johnson, P.J. Bjorkman, Identification of critical IgG binding epitopes on the neonatal Fc receptor., J. Mol. Biol. 274 (1997) 597-607. doi:10.1006/jmbi.1997.1388.

[23] J.T. Andersen, B. Dalhus, J. Cameron, M.B. Daba, A. Plumridge, L. Evans, et al., Structurebased mutagenesis reveals the albumin-binding site of the neonatal Fc receptor, Nat. Commun. 3 (2012) 610. doi:10.1038/ncomms1607.

[24] Wayne I. Lencer and Richard S. Blumberg, A passionate kiss, then run---exocytosis and recycling of IgG by FcRn, Trends Cell Biol. 15 (2005) 5-9. doi:10.1016/j.tcb.2004.11.004.

[25] P. Prabhat, Z. Gan, J. Chao, S. Ram, C. Vaccaro, S. Gibbons, et al., Elucidation of intracellular recycling pathways leading to exocytosis of the Fc receptor, FcRn, by using multifocal plane microscopy, Proc. Natl. Acad. Sci. (2007).

[26] R.J. Ober, C. Martinez, C. Vaccaro, E.S. Ward, Visualizing the Site and Dynamics of IgG Salvage by the MHC Class I-Related Receptor, FcRn, J. Immunol. (2015). doi:10.4049/jimmunol.172.4.2021.

[27] S. Mohanty, J. Kim, L.P. Ganesan, G.S. Phillips, J.M. Robinson, C.L. Anderson, Abundant Intracellular IgG in Enterocytes and Endoderm Lacking FcRn, PLoS One. 8 (2013) e70863. doi:10.1371/journal.pone.0070863.

[28] B. Gurbaxani, M. Dostalek, I. Gardner, Are endosomal trafficking parameters better targets for improving mAb pharmacokinetics than FcRn binding affinity? Mol. Immunol. 56 (2013) 660-674. doi:10.1016/j.molimm.2013.05.008.

[29] D. Sleep, J. Cameron, L.R. Evans, Albumin as a versatile platform for drug half-life extension, Biochim. Biophys. Acta - Gen. Subj. 1830 (2013) 5526-5534. doi:10.1016/j.bbagen.2013.04.023.

[30] D.M. Czajkowsky, J. Hu, Z. Shao, R.J. Pleass, Fc-fusion proteins: New developments and future perspectives, EMBO Mol. Med. 4 (2012) 1015-1028. doi:10.1002/emmm.201201379.

[31] Furukawa M, Tanaka R, Chuang VT, Ishima Y, Taguchi K, Watanabe H, Maruyama T, Otagiri M. Human serum albumin-thioredoxin fusion protein with long blood retention property is effective in suppressing lung injury. J Control Release. 154(2011) 189-95. doi: 10.1016/j.jconrel.2011.05.013.

[32] G.N. Cox, D.J. Smith, S.J. Carlson, A.M. Bendele, E. a. Chlipala, D.H. Doherty, Enhanced circulating half-life and hematopoietic properties of a human granulocyte colony- 
stimulating factor/immunoglobulin fusion protein, Exp. Hematol. 32 (2004) 441-449. doi:10.1016/j.exphem.2004.01.012.

[33] T. Ying, Y. Wang, Y. Feng, P. Prabakaran, R. Gong, L. Wang, Engineered antibody domains with significantly increased transcytosis and half-life in macaques mediated by FcRn, MAbs. (2015). doi:10.1080/19420862.2015.1067353.

[34] J. Seijsing, M. Lindborg, I. Höidén-Guthenberg, H. Bönisch, E. Guneriusson, F.Y. Frejd, et al., An engineered affibody molecule with $\mathrm{pH}$-dependent binding to $\mathrm{FcRn}$ mediates extended circulatory half-life of a fusion protein, Proc. Natl. Acad. Sci. 111 (2014) 17110-17115. doi:10.1073/pnas.1417717111.

[35] J.T. Sockolosky, M.R. Tiffany, F.C. Szoka, Engineering neonatal Fc receptor-mediated recycling and transcytosis in recombinant proteins by short terminal peptide extensions, Proc. Natl. Acad. Sci. 109 (2012) 16095-16100. doi:10.1073/pnas.1208857109.

[36] J.T. Andersen, M. Gonzalez-Pajuelo, S. Foss, O.J.B. Landsverk, D. Pinto, A. Szyroki, et al., Selection of nanobodies that target human neonatal Fc receptor., Sci. Rep. 3 (2013) 1118. doi:10.1038/srep01118.

[37] S.A. Jacobs, A.C. Gibbs, M. Conk, F. Yi, D. Maguire, C. Kane, et al., Fusion to a highly stable consensus albumin binding domain allows for tunable pharmacokinetics, Protein Eng. Des. Sel. (2015) 1-9. doi:10.1093/protein/gzv040.

[38] J.T. Andersen, B. Dalhus, D. Viuff, B.T. Ravn, K.S. Gunnarsen, A. Plumridge, et al., Extending serum half-life of albumin by engineering neonatal Fc receptor (FcRn) binding, J. Biol. Chem. 289 (2014) 13492-13502. doi:10.1074/jbc.M114.549832.

[39] J.T. Andersen, J. Cameron, A. Plumridge, L. Evans, D. Sleep, I. Sandlie, Single-chain Variable Fragment Albumin Fusions Bind the Neonatal Fc Receptor ( FcRn ) in a Species-dependent Manner----IMPLICATIONS FOR IN VIVO HALF-LIFE EVALUATION OF ALBUMIN FUSION, J. Biol. Chem. 288 (2013) 24277-24285. doi:10.1074/jbc.M113.463000.

[40] L.J. Holt, A. Basran, K. Jones, J. Chorlton, L.S. Jespers, N.D. Brewis, et al., Anti-serum albumin domain antibodies for extending the half-lives of short lived drugs, Protein Eng. Des. Sel. 21 (2008) 283-288. doi:10.1093/protein/gzm067.

[41] J.T. Sockolosky, S. Kivimäe, F.C. Szoka, Fusion of a short peptide that binds immunoglobulin $\mathrm{G}$ to a recombinant protein substantially increases its plasma half-life in mice, PLoS One. 9 (2014). doi:10.1371/journal.pone.0102566.

[42] J.T. Andersen, R. Pehrson, V. Tolmachev, M.B. Daba, L. Abrahmsén, C. Ekblad, Extending half-life by indirect targeting of the neonatal Fc receptor ( $F c R n)$ using a minimal albumin binding domain, J. Biol. Chem. 286 (2011) 5234-5241. doi:10.1074/jbc.M110.164848.

[43] F. Unverdorben, M. Hutt, O. Seifert, R.E. Kontermann, A Fab-Selective ImmunoglobulinBinding Domain from Streptococcal Protein G with Improved Half-Life Extension Properties, PLoS One. 10 (2015) e0139838. doi:10.1371/journal.pone.0139838.

[44] Y.A. Yeung, M.K. Leabman, J.S. Marvin, J. Qiu, C.W. Adams, S. Lien, et al., Engineering human IgG1 affinity to human neonatal Fc receptor: impact of affinity improvement on 
pharmacokinetics in primates. J. Immunol. 182 (2009) 7663-7671.

doi:10.4049/jimmunol.0804182.

[45] A.E. Nixon, J. Chen, D.J. Sexton, A. Muruganandam, A.J. Bitonti, J. Dumont, et al., Fully human monoclonal antibody inhibitors of the neonatal Fc receptor reduce circulating IgG in non-human primates, Front. Immunol. 6 (2015) 1-13. doi:10.3389/fimmu.2015.00176.

[46] M.J. Borrok, Y.L. Wu, N. Beyaz, X. Yu, V. Oganesyan, F.D. Acqua, P. Tusi, pH-Dependent Binding Engineering Reveals An FcRn Affinity Threshold Which Governs IgG Recycling J. Biochem. 290 (2014) 4282-4290 doi:10.1074/jbc.M114.603712.

[47] R.L. Shields, A.K. Namenuk, K. Hong, Y.G. Meng, J. Rae, J. Briggs, et al., High Resolution Mapping of the Binding Site on Human IgG1 for FcyRI, FcyRII, FcyRIII, and FcRn and Design of IgG1 Variants with Improved Binding to the FcyR, J. Biol. Chem. 276 (2001) 6591-6604. doi:10.1074/jbc.M009483200.

[48] G.J. Christianson, V.Z. Sun, S. Akilesh, E. Pesavento, G. Proetzel, D.C. Roopenian, Monoclonal antibodies directed against human FcRn and their applications, MAbs. 4 (2012) 208-216. doi:10.4161/mabs.4.2.19397.

[49] J. Sambrook, D. W. Russell, Growing bacteriophage M13 in liquid culture. CSH Protoc. 1 (2006).

[50] D. Kim, S. Chu, S. Kim, Y. Park, S. Kim, Fc fusion to Glucagon-like peptide-1 inhibits degradation by human DPP-IV, increasing its half-life in serum and inducing a potent activity for human GLP-1 receptor activation, BMB Rep. 42 (2009) 212-216.

[51] M.J. Moon, H.Y. Kim, S.G. Kim, J. Park, D.S. Choi, J.-I. Hwang, et al., Tyr1 and lle7 of glucosedependent insulinotropic polypeptide (GIP) confer differential ligand selectivity toward GIP and glucagon-like peptide-1 receptors, Mol. Cells. 30 (2010) 149-154. doi:10.1007/s10059010-0100-5.

[52] A. Kolate, D. Baradia, S. Patil, I. Vhora, G. kore, A. Misra, PEG-A versatile conjugating ligand for drug and drug delivery systems, J Control Release. 192 (2014) 67-81. doi:10.1016/j.jconrel.2014.06.046.

[53] M. Schlapschy, I. Theobald, H. Mack, M. Schottelius, H.J. Wester, A. Skerra, Fusion of a recombinant antibody fragment with a homo-amino-acid polymer: Effects on biophysical properties and prolonged plasma half-life, Protein Eng. Des. Sel. 20 (2007) 273-284. doi:10.1093/protein/gzm020.

[54] C. Chen, A. Constantinou, K. a. Chester, B. Vyas, K. Canis, S.M. Haslam, et al., Glycoengineering approach to half-life extension of recombinant biotherapeutics, Bioconjug. Chem. 23 (2012) 1524-1533. doi:10.1021/bc200624a.

[55] E.S. Ward, S.C. Devanaboyina, R.J. Ober, Targeting FcRn for the modulation of antibody dynamics, Mol. Immunol. (2015). doi:10.1016/j.molimm.2015.02.007.

[56] B.A. Baldo, Chimeric Fusion Proteins Used for Therapy: Indications, Mechanisms, and Safety, Drug Saf. (2015) 455-479. doi:10.1007/s40264-015-0285-9.

[57] R.E. Kontermann, Strategies to extend plasma half-lives of recombinant antibodies, BioDrugs. 23 (2009) 93-109. doi:10.2165/00063030-200923020-00003.

[58] J.T. Sockolosky, F.C. Szoka, The neonatal Fc receptor, FcRn, as a target for drug delivery and therapy, Adv. Drug Deliv. Rev. (2015). doi:10.1016/j.addr.2015.02.005.

[59] L. Liu, A.M. Garcia, H. Santoro, Y. Zhang, K. McDonnell, J. Dumont, et al., Amelioration of 
experimental autoimmune myasthenia gravis in rats by neonatal FcR blockade., J. Immunol. 178 (2007) 5390-5398. doi:10.4049/jimmunol.178.8.5390.

[60] W.M.Pardridge, Ruben J. Boado, Jeff Zhiqiang Lu, Eric Ka-Wai Hui, IgG-single chain Fv fusion protein therapeutic for Alzheimer's disease : Expression in CHO cells and pharmacokinetics and brain delivery in the Rhesus monkey NIH Public Access, Biotechnol Bioeng. 105 (2010) 627-635. doi:10.1002/bit.22576.

[61] P. Monnier, R. Vigouroux, N. Tassew, In Vivo Applications of Single Chain Fv (Variable Domain) (scFv) Fragments, Antibodies. 2 (2013) 193-208. doi:10.3390/antib2020193.

[62] L.L. Baggio, D.J. Drucker, Biology of Incretins: GLP-1 and GIP, Gastroenterology. 132 (2007) 2131-2157. doi:10.1053/j.gastro.2007.03.054.

[63] H.J. C, Orskov, Wettergren A, Biological effects and metabolic rates of GLP-1 7-37 amide and GLP-1 7-37 in healthy subjects are indistinguishable, Diabetes. 42 (1993) 658-661. doi:10.2337/diab.42.5.658

[64] R.L. O'Connor-Semmes, J. Lin, R.J. Hodge, S. Andrews, J. Chism, a Choudhury, et al., GSK2374697, a Novel Albumin-Binding Domain Antibody (AlbudAb), Extends Systemic Exposure of Exendin-4: First Study in Humans-PK/PD and Safety, Clin. Pharmacol. Ther. 96 (2014) 704-712. doi:10.1038/clpt.2014.187.

[65] A.J. Garber, Long-acting glucagon-like peptide 1 receptor agonists: A review of their efficacy and tolerability, Diabetes Care. 34 (2011) 279-284. doi: 10.2337/dc11-s231.

[66] A. P. West, Jr., P. J. Bjorkman, Crystal structure and immunoglobulin G binding properties of the human major histocompatibility complex-related Fc receptor, Biochemistry 39 (2000) 9698-9708. DOI: 10.1021/bi000749m

[67] Y.N. Abdiche, Y.A. Yeung, J. Chaparro-Riggers, I. Barman, P. Strop, S.M. Chin, et al., The neonatal Fc receptor ( $\mathrm{FCRn}$ ) binds independently to both sites of the IgG homodimer with identical affinity, MAbs. 7 (2015) 331-343. doi:10.1080/19420862.2015.1008353. 